\title{
RESEARCH
}

Open Access

\section{Cardiovascular magnetic resonance imaging derived septal curvature in neonates with bronchopulmonary dysplasia associated pulmonary hypertension}

Paul J. Critser 1,20, Nara S. Higano², Sean M. Lang ${ }^{1,3}$, Paul S. Kingma ${ }^{3,4}$, Robert J. Fleck ${ }^{3,5}$, Russel Hirsch ${ }^{1,3}$, Michael D. Taylor ${ }^{1,3}$ and Jason C. Woods $2,3,5^{*}$

\begin{abstract}
Background: Bronchopulmonary dysplasia (BPD) associated with pulmonary hypertension (PH) is a significant source of morbidity and mortality in premature infants. Recent advances have allowed the use of cardiovascular magnetic resonance (CMR) in the assessment of respiratory and cardiac disease in infants with BPD. In adults and older pediatric patients, decreased CMR interventricular septal curvature correlates with increased mean pulmonary artery pressure and pulmonary vascular resistance. The current study sought to determine the relationship of CMR derived septal curvature in neonates with BPD and BPD-PH with a need for PH therapy.

Methods: Forty moderate or severe BPD and 12 mild BPD or control infants were imaged without contrast between 38 and 47 weeks post-menstrual age on a neonatal-sized, neonatal intensive care unit-sited 1.5 T CMR scanner. CMR indices including eccentricity index (CMR-EI) and septal curvature were measured and compared to BPD severity and clinical outcomes including hospital length of stay (LOS), duration of respiratory support, respiratory support level at discharge and PH therapy.

Results: CMR-EI was directly associated and septal curvature was inversely associated with BPD severity. In a univariate analysis, CMR-El and septal curvature were associated with increased hospital LOS, duration of respiratory support, respiratory support at hospital discharge, and need for PH therapy. In multivariable analysis CMR-El was associated with hospital LOS and duration of respiratory support and septal curvature was associated with respiratory support at hospital discharge. Septal curvature was the only clinical or CMR variable associated with need for $\mathrm{PH}$ therapy $\left(R^{2}=\right.$ $0.66, p=0.0014)$ in multivariable analysis demonstrating improved discrimination beyond CMR-El.

(Continued on next page)
\end{abstract}

\footnotetext{
* Correspondence: jason.woods@cchmc.org

${ }^{2}$ Center for Pulmonary Imaging Research, Cincinnati Children's Hospital Medical Center, Cincinnati, OH, USA

${ }^{3}$ Department of Pediatrics, University of Cincinnati College of Medicine, Cincinnati, OH 45229, USA

Full list of author information is available at the end of the article
}

(c) The Author(s). 2020 Open Access This article is licensed under a Creative Commons Attribution 4.0 International License, which permits use, sharing, adaptation, distribution and reproduction in any medium or format, as long as you give appropriate credit to the original author(s) and the source, provide a link to the Creative Commons licence, and indicate if changes were made. The images or other third party material in this article are included in the article's Creative Commons licence, unless indicated otherwise in a credit line to the material. If material is not included in the article's Creative Commons licence and your intended use is not permitted by statutory regulation or exceeds the permitted use, you will need to obtain permission directly from the copyright holder. To view a copy of this licence, visit http://creativecommons.org/licenses/by/4.0/ The Creative Commons Public Domain Dedication waiver (http://creativecommons.org/publicdomain/zero/1.0/) applies to the data made available in this article, unless otherwise stated in a credit line to the data. 


\begin{abstract}
(Continued from previous page)
Conclusions: CMR derived septal curvature correlates significantly with clinical outcomes including hospital LOS, duration of respiratory support, respiratory support level at hospital discharge, and PH therapy in neonates with BPD and BPD-PH. Further, CMR derived septal curvature demonstrated improved discrimination of need for $\mathrm{PH}$ therapy and respiratory support at discharge compared to clinical variables and other CMR indices, supporting septal curvature as a non-invasive marker of $\mathrm{PH}$ in this population with potential to guide management strategies.
\end{abstract}

Keywords: Bronchopulmonary dysplasia, Cardiovascular magnetic resonance, Interventricular septal curvature, Neonatal lung disease, Pulmonary hypertension

\section{Background}

Bronchopulmonary dysplasia (BPD) is a significant contributor to morbidity and mortality in premature infants [1-3]. Alterations in lung development in BPD infants are associated with pulmonary vascular disease and pulmonary hypertension (PH). BPD associated PH (BPD$\mathrm{PH}$ ) is associated with increased BPD severity, short and late term respiratory outcomes and mortality, and $\mathrm{PH}$ secondary to BPD is associated with increased mortality compared to other etiologies of $\mathrm{PH}[2,4-11]$.

While invasive hemodynamic assessment with cardiac catheterization remains the gold standard for diagnosis of $\mathrm{PH}$, it may be challenging in critically ill neonates. Increasingly, cardiovascular magnetic resonance (CMR) is used for non-invasive assessment of $\mathrm{PH}$ in adult and older pediatric populations and recent advances in CMR pulse sequences and equipment have allowed for assessment of the lung parenchyma and cardiac morphology of infants with BPD and BPD-PH [12-20].

In particular CMR derived interventricular septal curvature, which provides a quantitative assessment of the interventricular septum throughout the cardiac cycle, has been associated with mean pulmonary artery pressure and pulmonary vascular resistance in adult and pediatric patients [17, 21-24]. However, no studies have assessed the relationship of septal curvature with $\mathrm{PH}$ in the BPD population.

The current study sought to assess the correlation of CMR derived septal curvature with short term clinical outcomes in neonates with BPD and BPD-PH. We hypothesized that decreased septal curvature would be associated with BPD severity, need for respiratory support and pulmonary vasodilator therapy, and demonstrate improved discrimination compared to other CMR indices.

\section{Methods}

\section{Study subjects}

Neonates included in the study were enrolled with Institutional Review Board approval. Inclusion criteria for neonates with BPD included BPD diagnosis per the 2001 National Institute of Child Health and Human Development and National Heart, Blood, and Lung Institute consensus definition [25] and post-menstrual age of 48 weeks or less at the time of CMR. Inclusion criteria for control infants included full-term birth ( $\geq 37$ weeks gestational age) or pre-term birth in the absence of BPD, no clinically significant lung disease, and post-menstrual age 48 weeks or less at CMR. Control subjects were comprised of infants with primary neurologic or gastrointestinal diagnosis. Exclusion criteria for all study subjects consisted of evidence of significant genetic abnormalities or congenital malformations, evidence of respiratory infection at time of CMR, and standard CMR exclusion criteria.

\section{CMR protocol}

Research CMR acquisitions were performed using a 1.5 $\mathrm{T}$ scanner (originally manufactured by ONI Medical Systems; currently GE Healthcare, Waukesha, Wisconsin, USA) sited in the neonatal intensive care unit [26]. CMR studies were conducted free breathing and without sedation unless indicated as part of their clinical care. CMR sequences used for cardiac analysis included a short-axis, retrospective electrocardiogram-gated balanced steady-state free-precession (bSSFP) imaging acquisition and an axial electrocardiogram-triggered double inversion-recovery fast spin echo acquisition. As previously described typical shortaxis bSSFP acquisition parameters included: echo time $=$ $1.6 \mathrm{~ms}$; repetition time $=3.7 \mathrm{~ms}$; flip angle $=45$ degrees; ef fective temporal resolution $=20 \mathrm{~ms}$; field of view $28-32 \mathrm{~cm}$; pixel resolution $1.09-1.25 \mathrm{~mm}$; slice thickness $=5-6 \mathrm{~mm}$; number of averages $=3$; and estimated scan time $=2 \mathrm{~min}$ and typical fast spin echo acquisition parameters included: echo time $=43.0 \mathrm{~ms}$; repetition time $=736.2 \mathrm{~ms}$; flip angle $=$ 90 degrees; field of view $16-17 \mathrm{~cm}$; pixel resolution 0.63 $0.66 \mathrm{~mm}$; slice thickness $=4 \mathrm{~mm}$; number of averages $=3$; and estimated scan time $=3 \min [20]$.

\section{CMR image analysis}

The right ventricle (RV) and left ventricle (LV) were contoured throughout the cardiac cycle in the short axis stack. RV end systolic volume indexed to body surface area (RVESVi), RV end diastolic volume indexed to body surface area (RVEDVi), RV mass indexed to body surface area, LV end systolic volume indexed to body surface area (LVESVi), LV end diastolic volume indexed to body 
surface area (LVEDVi), LV and RV ejection fraction $(\mathrm{EF})$, and cardiac index (CI) were determined (cvi42, Circle Cardiovascular Imaging, Calgary, Canada). CMREccentricity Index (CMR-EI) was measured as the ratio of the lateral to anterior-posterior diameter of the LV at end systole from the short axis stack at the level of the papillary muscles (Fig. 1).

Septal curvature was measured from the short axis stack at the level of the papillary muscles as previously described [17] using ImageJ (National Institutes of Health, Bethesda, Maryland, USA). A total of 8 points were placed along the LV lateral wall contoured from anterolateral to inferolateral septum and the interventricular septum contoured from RV insertion point to RV insertion point. Contours were propagated throughout the cardiac cycle and manually adjusted across 20 phases. Curvature analysis was performed for each phase of the cardiac cycle. The septal curvature was determined from the ratio of the curvature of the interventricular septum and LV lateral wall. Lower septal curvature values represent increased septal flattening with a negative septal curvature representing septal bowing into the LV. The minimum septal curvature was the minimum value of the septal curvature throughout the cardiac cycle (Fig. 1). All measurements were conducted by a single cardiologist. A second cardiologist analyzed 10 (25\%) randomly selected studies, and interobserver and intraobserver intraclass correlation coefficients were determined.

\section{Statistical analysis}

Univariate ANOVA tests were used to determine group differences in CMR indices, birth weight, gestational age,
BPD severity, and short term clinical outcomes including length of stay (LOS), duration of respiratory support, respiratory support at hospital discharge, and need for $\mathrm{PH}$ therapy for three groups: subjects who did not receive $\mathrm{PH}$ therapy, patients who received $\mathrm{PH}$ therapy in the hospital, but not at discharge, and patients who received $\mathrm{PH}$ therapy in the hospital and at discharge. Univariate ANOVA tests were used to determine association of septal curvature with short term outcomes and of CMR indices and clinical variables with septal curvature. Mean and standard deviation are reported for parametric group data and mean and interquartile range for nonparametric group data.

Multivariable linear regression models were developed to assess the association of CMR indices and clinical variables with clinical outcomes using forward stepwise model with $p$-value $\leq 0.10$ for inclusion in the original model and p-value $\leq 0.05$ to remain in the final model. All analyses were performed in JMP 14.3 (SAS Institute Inc. Cary, North Carolina, USA).

\section{Results \\ Patient demographics}

Demographics for the cohort are shown in Table 1. The study cohort consisted of 52 neonates including 40 with moderate or severe BPD and 12 mild BPD or control infants. The median age at CMR was 41 weeks postmenstrual age [interquartile range (IQR) 39.6-42.5] and median heart rate was 157 beats per minute (IQR 143166). CMR was completed in all infants without adverse events and septal curvature was measured in 46 (88\%)
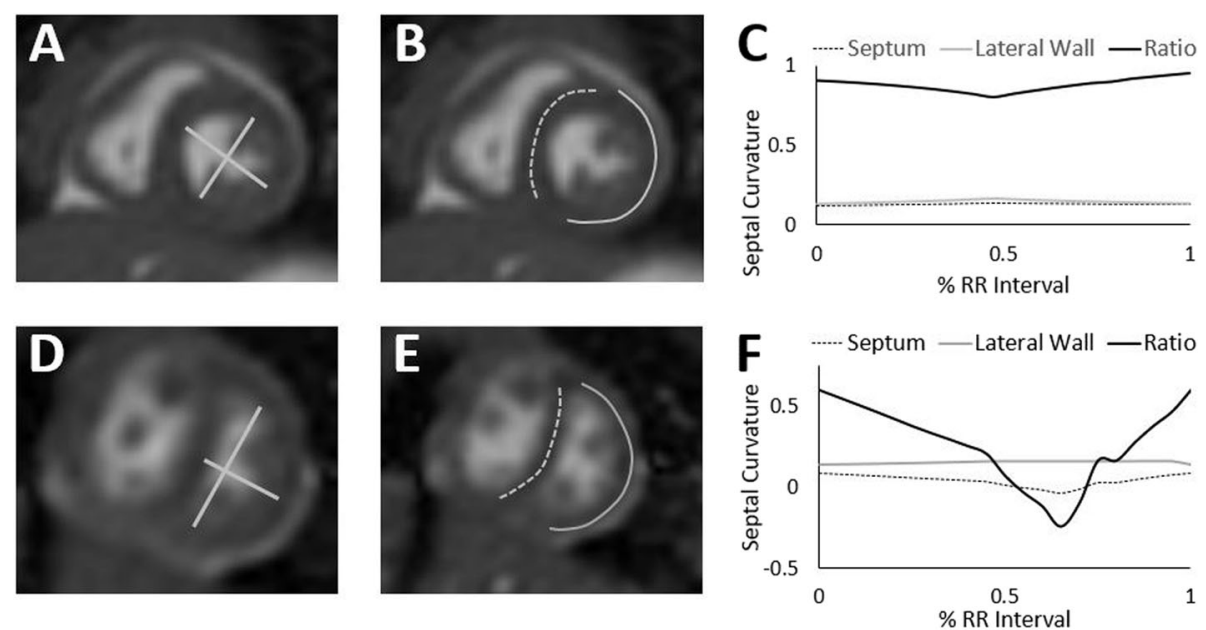

Fig. 1 Cardiovascular magnetic resonance (CMR) eccentricity index (EI) and septal curvature for patients without septal flattening (a, b, c) and with septal flattening $(\mathbf{d}, \mathbf{e}, \mathbf{f})$. CMR eccentricity index was derived as the ratio of the lateral to anterior-posterior diameter of the left ventricle (LV) at end systole $(\mathbf{a}, \mathbf{d})$. CMR septal curvature was derived as the ratio of curvature of the septum (dashed line) and lateral wall (solid line) throughout the cardiac cycle $(\mathbf{b}, \mathbf{e})$; CMR images $(\mathbf{b}, \mathbf{e})$ shown here demonstrate the time-point at which minimum septal curvature occurred in the two patients. Septal curvature across the cardiac cycle for the septum (dashed line), lateral wall (grey line) and ratio of septum to lateral wall (black line, c, $\mathbf{f}$ ) 
Table 1 Demographic data for the study cohort

\begin{tabular}{|c|c|c|c|c|}
\hline & No PH therapy & PH therapy in hospital & PH therapy at DC & $P$ value \\
\hline Birth weight (grams) & $1236 \pm 765$ & $622 \pm 162$ & $651 \pm 383$ & 0.0143 \\
\hline Gestational age (weeks) & $29.0 \pm 4.9$ & $25.9 \pm 2.7$ & $25.4 \pm 2.0$ & 0.0298 \\
\hline Severe BPD n (\%) & $13(38)$ & $8(100)$ & $10(100)$ & 0.0009 \\
\hline Hospital LOS (days) & $144.8 \pm 102.2$ & $263.5 \pm 141.5$ & $297.1 \pm 177.1$ & 0.0021 \\
\hline Total Respiratory Support (days) & $146.9 \pm 148.9$ & $350.3 \pm 176.6$ & $370.4 \pm 228.5$ & $<0.001$ \\
\hline Discharge Respiratory Support (Vent or death) n (\%) & $0(0)$ & $5(62)$ & $9(90)$ & $<0.001$ \\
\hline
\end{tabular}

Data are mean \pm standard deviation, unless otherwise noted

Abbreviations: $P H$ pulmonary hypertension, BPD bronchopulmonary dysplasia, LOS length of stay

infants. The interobserver intraclass correlation coefficient for septal curvature was 0.953 with $95 \%$ confidence interval $0.820-0.989$ and the intraobserver intraclass correlation coefficient was 0.889 with $95 \%$ confidence interval 0.614-0.972.

\section{Pulmonary hypertension therapy}

Eighteen (35\%) of the infants received PH therapy in the hospital. PH therapy was discontinued prior to discharge in eight (44\%) infants treated with $\mathrm{PH}$ therapy in the hospital. Need for PH therapy was inversely correlated with birthweight and gestational age and directly correlated with hospital LOS, duration of total respiratory support, and discharge respiratory support.

CMR indices RV mass, CMR-EI, and septal curvature were associated with $\mathrm{PH}$ therapy. Higher RV mass $(p=$ $0.04)$, CMR-EI $(p<0.001)$ and lower septal curvature $(<$ 0.001 ) were associated with $\mathrm{PH}$ therapy on univariate analysis. CMR indices RVESVi, RVEDVi, LVESVi, LVEDVi, RVEF, LVEF, and CI were not significantly associated with need for $\mathrm{PH}$ therapy (Table 2). Clinical variables including gestational age $(p=0.03)$, birthweight $(p=0.01)$, and BPD severity $(p=0.004)$ were associated with need for $\mathrm{PH}$ therapy on univariate analysis. On multivariable analysis including clinical variables and CMR indices, only septal curvature was independently associated with $\mathrm{PH}$ therapy (Table 3). The median percent of the cardiac cycle for minimum septal curvature was 53\% (IQR 42-67\%), 54\% (IQR 51-75\%), and 60\% (IQR $58-74 \%$ ) in patients never treated with PH therapy, treated with $\mathrm{PH}$ therapy in hospital but not at discharge, and patients treated with $\mathrm{PH}$ therapy at discharge $(p=$ $0.16)$.

\section{Respiratory outcomes}

The median hospital LOS was 166.0 days (IQR 109.5$237.5)$ and the median length of total respiratory support was 167 (86.0-313.5) days. On univariate analysis septal curvature was inversely associated with hospital LOS $\left(R^{2}=0.17\right.$, parameter estimate \pm standard error $=-$ $172.0 \pm 56.6$, and $p$ value $=0.004)$, and length of total respiratory support $\left(R^{2}=0.29\right.$, parameter estimate \pm standard error $=-305.3 \pm 74.3$, and $p$ value $=0.0002$ ) Including clinical variables and CMR indices in multivariable analysis hospital LOS was associated with BPD severity and CMR-EI, and length of total respiratory support was associated with BPD severity, body weight, and CMR-EI (Table 3). Twelve infants were discharged

Table 2 Cardiac MRI data for the study cohort

\begin{tabular}{|c|c|c|c|c|c|}
\hline & $\mathrm{N}$ & No PH therapy & PH therapy in hospital & PH therapy at DC & $P$ value \\
\hline RVEDVi (ml/m2) & 46 & $40.6 \pm 10.7$ & $37.7 \pm 16.7$ & $43.8 \pm 8.5$ & 0.56 \\
\hline RVESVi (ml/m2) & 46 & $15.9 \pm 5.0$ & $15.0 \pm 4.5$ & $19.4 \pm 6.5$ & 0.17 \\
\hline RVEF (\%) & 46 & $60.6 \pm 6.9$ & $60.7 \pm 6.2$ & $56.6 \pm 12.3$ & 0.42 \\
\hline RV mass (g/m2) & 46 & $13.1 \pm 3.6$ & $15.4 \pm 5.7$ & $16.7 \pm 3.2$ & 0.04 \\
\hline LVEDVi (ml/m2) & 46 & $43.6 \pm 9.7$ & $43.1 \pm 16.1$ & $37.1 \pm 7.7$ & 0.26 \\
\hline LVESVi (ml/m2) & 46 & $17.1 \pm 6.0$ & $16.4 \pm 8.5$ & $14.0 \pm 3.1$ & 0.41 \\
\hline LVEF (\%) & 46 & $61.4 \pm 6.6$ & $61.4 \pm 5.7$ & $62.9 \pm 3.9$ & 0.79 \\
\hline $\mathrm{Cl}(\mathrm{L} / \mathrm{min} / \mathrm{m} 2)$ & 46 & $4.3 \pm 1.4$ & $4.0 \pm 1.4$ & $3.7 \pm 0.7$ & 0.39 \\
\hline CMR-El & 48 & $1.09 \pm 0.10$ & $1.15 \pm 0.15$ & $1.32 \pm 0.22$ & $<0.001$ \\
\hline Septal Curvature & 46 & $0.77 \pm 0.18$ & $0.60 \pm 0.19$ & $0.06 \pm 0.3$ & $<0.001$ \\
\hline
\end{tabular}

Data are mean \pm standard deviation

Abbreviations: RVEDVi RV end diastolic volume indexed to body surface area, RVESVi RV end systolic volume indexed to body surface area, RVEF RV ejection fraction, LVEDVi LV end diastolic volume indexed to body surface area, LVESVi LV end systolic volume indexed to body surface area, LVEF LV ejection fraction, CI cardiac index, CMR cardiovascular magnetic resonance, El eccentricity index 
Table 3 Predictors of short-term clinical outcomes in multivariable analysis

\begin{tabular}{|c|c|c|c|}
\hline & $R^{2}$ & Parameter estimate \pm SE & $P$ value \\
\hline Hospital LOS & 0.49 & & \\
\hline BPD Severity & & $-43.4 \pm 17.4$ & 0.0167 \\
\hline CMR-El & & $343.87 \pm 107.50$ & 0.0026 \\
\hline Length of Total Respiratory Support & 0.55 & & \\
\hline Body weight & & $-0.072 \pm 0.033$ & 0.0324 \\
\hline BPD Severity & & $-57.1 \pm 23.1$ & 0.0177 \\
\hline CMR-El & & $539.71 \pm 142.8$ & 0.005 \\
\hline Discharge Respiratory Support & 0.47 & & \\
\hline $\begin{array}{l}\text { BPD Severity } \\
\text { (severe vs moderate) }\end{array}$ & & $-2.1 \pm 0.93$ & 0.0245 \\
\hline Septal curvature & & $4.49 \pm 1.49$ & 0.0027 \\
\hline PH Therapy & 0.66 & & \\
\hline Septal curvature & & $11.37 \pm 3.55$ & 0.0014 \\
\hline
\end{tabular}

Abbreviations: $L O S$ length of stay, $B P D$ bronchopulmonary dysplasia, $P H$ pulmonary hypertension, $E$ el eccentricity index

from the hospital on supplemental oxygen, 15 required tracheostomy, and two died of respiratory complications. Septal curvature was associated with level of discharge respiratory support on univariate analysis $\left(R^{2}=0.45, p\right.$ value $<0.0001)$ and septal curvature and BPD severity were the only clinical or CMR variables significantly associated on multivariable analysis.

\section{Parameters associated with septal curvature}

The following variables were associated with septal curvature on univariate analysis: birthweight $\left(R^{2}=0.17\right.$, $p=0.005)$, gestational age $\left(R^{2}=0.15, p=0.007\right)$, BPD Severity $\left(R^{2}=0.17, p=0.018\right)$, RV mass $\left(R^{2}=0.25, p=\right.$ 0.0005), CMR-EI $\left(R^{2}=0.55, p=<0.0001\right)$, RVEDVi $\left(R^{2}=0.10, p=0.035\right)$, and RVESVi $\left(R^{2}=0.21, p=0.002\right)$. On multivariable analysis including clinical variable and excluding CMR indices, gestational age was the only independent variable associated with septal curvature $\left(R^{2}=0.15, p=0.007\right)$.

\section{Discussion}

This study is the first to evaluate septal curvature in neonates with $\mathrm{PH}$. CMR derived septal curvature was able to be determined in the vast majority of patients and was independently associated with level of respiratory support at hospital discharge and need for PH therapy, performing better than clinical and other CMR indices such as RV mass and CMR-EI. Initiation of PH therapy in this population is not currently standardized and often relies on qualitative assessment of clinical and echocardiographic data. These data suggest that septal curvature is a quantitative imaging marker that could allow for risk stratification and initiation of early therapy in neonates with BPD-PH.
Similar to previous studies, 35\% of the cohort of BPD infants had $\mathrm{PH}$ with resolution of $\mathrm{PH}$ in $44 \%$ of neonates with BPD-PH $[10,11]$. Additionally, BPD infants with $\mathrm{PH}$ had lower gestational age, lower birthweight, increased BPD severity, longer hospital LOS, duration of respiratory support, and increased level of respiratory support at hospital discharge compared to infants without $\mathrm{PH}$ consistent with prior studies in this population [4-6, 27]. BPD severity, gestational age, and birthweight were also associated with septal curvature in univariate analysis. Gestational age, which has previously been shown to correlate with BPD severity and CMR-EI, was the only clinical variable associated with septal curvature in multivariable analysis [20, 27].

Respiratory outcomes were correlated with CMR indices of septal flattening. In multivariable analysis, including clinical and CMR parameters, CMR-EI was associated with hospital LOS and duration of total respiratory support and septal curvature was associated with level of respiratory support at hospital discharge in addition to BPD severity. These data support an association of cardiac indices septal curvature and CMR-EI with short-term respiratory outcomes in BPD infants.

Septal curvature was the only independent variable associated with need for PH therapy in multivariable analysis. This is consistent with prior reports which have demonstrated that CMR derived minimum septal curvature and echocardiography derived septal curvature measured at end systole are associated with elevated RV pressure $[17,28,29]$. In the report by Pandya et al. CMR derived septal curvature correlated with mean pulmonary artery pressure and pulmonary vascular resistance in older pediatric $\mathrm{PH}$ patients [17]. In that cohort normal controls had septal curvature $>0.9$, while $\mathrm{PH}$ patients had septal curvature $<0.8$. Similarly in this study cohort 
all patients discharged on $\mathrm{PH}$ therapy had septal curvature $<0.5$, while only two patients who never received $\mathrm{PH}$ therapy had septal curvature $<0.5$. The septal curvature for the all infants in the present cohort was $<1.0$, which is lower than CMR derived septal curvature reported in healthy children and may be due to younger age and BPD associated lung disease [17].

Previous reports have demonstrated that EI derived from echocardiography is higher in infants with persistent pulmonary hypertension and in infants with BPDPH compared to controls [30, 31]. Additionally, CMR-EI has been shown to correlate with $\mathrm{PH}$ therapy in neonates with BPD-PH [20]. CMR-EI was modestly correlated with septal curvature in this cohort. Eccentricity index provides a quantitative assessment of interventricular septal flattening at the end of LV systole, while septal curvature provides a continuous assessment throughout the cardiac cycle. Patients with $\mathrm{PH}$ may have prolonged RV contraction resulting in maximal septal flattening (minimum septal curvature) after the end of LV systole [32]. Pandya et al. demonstrated that minimal septal curvature in pediatric $\mathrm{PH}$ patients occurred after aortic valve closure, during early LV diastole [17]. Indeed, in the current study the majority of patients receiving $\mathrm{PH}$ therapy had minimum septal curvature between 58 and $74 \%$ of the cardiac cycle. By capturing maximal septal flattening, minimum septal curvature may provide a more sensitive marker of $\mathrm{PH}$.

While cardiac catheterization remains the gold standard for the diagnosis of $\mathrm{PH}, \mathrm{CMR}$ offers an alternative non-invasive assessment of $\mathrm{PH}$. Recent studies have correlated CMR metrics, including CMR derived septal curvature with invasive hemodynamic data in older pediatric and adult patients $[17,33]$. This study suggests CMR derived septal curvature provides a non-invasive marker of PH in BPD infants which can be readily obtained from routine CMR protocols without the need for sedation associated with cardiac catheterization.

This study has several limitations including the single center study design and retrospective analysis, increased percentage of moderate to severe BPD infants, and the lack of normative CMR data in term and preterm infants without BPD. Additional studies are needed to define normative septal curvature in neonates and to confirm the associations in larger cohorts.

\section{Conclusions}

In this study of neonates with BPD and BPD-PH, CMR derived septal curvature was associated with respiratory support at discharge and $\mathrm{PH}$ therapy with improved discrimination compared to other CMR indices including CMR-EI. These data support septal curvature as a noninvasive marker of $\mathrm{PH}$ in this population with potential to guide treatment strategies.

\section{Supplementary information}

Supplementary information accompanies this paper at https://doi.org/10. 1186/s12968-020-00643-x.

Additional file 1 : Figure S1. Representative cine images of infants without septal flattening $(A)$ and with septal flattening (B).

\section{Abbreviations}

BPD: Bronchopulmonary dysplasia; bSSFP: Balanced steady state free precession; Cl: Cardiac index; CMR: Cardiovascular magnetic resonance; EF: Ejection fraction; El: Eccentricity index; LOS: Length of stay; LV: Left ventricle/left ventricular; LVEDVI: Left ventricular end diastolic volume index; LVEF: Left ventricular ejection fraction; LVESVI: Left ventricular end systolic volume index; PH: Pulmonary hypertension; RV: Right ventricle/right ventricular; RVEDVI: Right ventricular end diastolic volume indexed to body surface area; RVEF: Right ventricular ejection fraction; RVESVI: Right ventricular end systolic volume index

\section{Acknowledgements}

Not applicable.

\section{Authors' contributions}

Paul Critser, Nara Higano, Sean Lang, and Jason Woods contributed to the experimental design, data analysis, drafting and revision of the work. Russel Hirsch, Paul Kingma, Robert Fleck, and Michael Taylor contributed to the experimental design, data analysis, and revision of the work. The author(s) read and approved the final manuscript.

\section{Funding}

NSH was supported by NIH T32 HLD07752. JCW and PSK were supported by $\mathrm{NIH} \mathrm{RO1} \mathrm{HL146689.}$

\section{Availability of data and materials}

The datasets used and analyzed during the current study are available from the corresponding author on reasonable request.

Ethics approval and consent to participate

Neonates included in the study were enrolled with Institutional Review Board approval and with parental consent

Consent for publication

Not applicable.

\section{Competing interests}

The authors have no competing interests.

\section{Author details}

${ }^{1}$ Heart Institute, Cincinnati Children's Hospital Medical Center, Cincinnati, $\mathrm{OH}$, USA. ${ }^{2}$ Center for Pulmonary Imaging Research, Cincinnati Children's Hospital Medical Center, Cincinnati, OH, USA. ${ }^{3}$ Department of Pediatrics, University of Cincinnati College of Medicine, Cincinnati, $\mathrm{OH} 45229$, USA. ${ }^{4}$ Division of Neonatology and Pulmonary Biology, Cincinnati Children's Hospital Medical Center, Cincinnati, OH, USA. ${ }^{5}$ Department of Radiology, Cincinnati Children's Hospital Medical Center, 3333 Burnet Avenue, ML 5033, Cincinnati, OH 45229, USA.

Received: 10 January 2020 Accepted: 29 May 2020

Published online: 23 July 2020

References

1. Baraldi E, Filippone M. Chronic lung disease after premature birth. N Engl J Med. 2007;357(19):1946-55.

2. Mourani PM, Mandell EW, Meier M, Younoszai A, Brinton JT, Wagner BD, et al. Early pulmonary vascular disease in preterm infants is associated with late respiratory outcomes in childhood. Am J Respir Crit Care Med. 2018; 199:1020-7.

3. Higgins RD, Jobe AH, Koso-Thomas M, Bancalari E, Viscardi RM, Hartert TV, et al. Bronchopulmonary dysplasia: executive summary of a workshop. J Pediatr. 2018;197:300-8. 
4. Mourani PM, Sontag MK, Younoszai A, Miller Jl, Kinsella JP, Baker CD, et al. Early pulmonary vascular disease in preterm infants at risk for bronchopulmonary dysplasia. Am J Respir Crit Care Med. 2015;191(1):87-95.

5. An HS, Bae EJ, Kim GB, Kwon BS, Beak JS, Kim EK, et al. Pulmonary hypertension in preterm infants with bronchopulmonary dysplasia. Korean Circ J. 2010;40(3):131-6.

6. Lagatta JM, Hysinger EB, Zaniletti I, Wymore EM, Vyas-Read S, Yallapragada S, et al. The impact of pulmonary hypertension in preterm infants with severe bronchopulmonary dysplasia through 1 year. J Pediatr. 2018;203:218-24 e3.

7. Bhat R, Salas AA, Foster C, Carlo WA, Ambalavanan N. Prospective analysis of pulmonary hypertension in extremely low birth weight infants. Pediatrics. 2012;129(3):e682-9.

8. Khemani E, McElhinney DB, Rhein L, Andrade O, Lacro RV, Thomas KC, et al. Pulmonary artery hypertension in formerly premature infants with bronchopulmonary dysplasia: clinical features and outcomes in the surfactant era. Pediatrics. 2007;120(6):1260-9.

9. Mirza H, Ziegler J, Ford S, Padbury J, Tucker R, Laptook A. Pulmonary hypertension in preterm infants: prevalence and association with bronchopulmonary dysplasia. J Pediatr. 2014;165(5):909-14 e1.

10. Altit G, Bhombal S, Hopper RK, Tacy TA, Feinstein J. Death or resolution: the "natural history" of pulmonary hypertension in bronchopulmonary dysplasia. J Perinatol. 2019;39(3):415-25.

11. Cohen JL, Nees SN, Valencia GA, Rosenzweig EB, Krishnan US. Sildenafil use in children with pulmonary hypertension. J Pediatr. 2019;205:29-34 e1.

12. Friesen RM, Schafer M, Ivy DD, Abman SH, Stenmark K, Browne LP, et al. Proximal pulmonary vascular stiffness as a prognostic factor in children with pulmonary arterial hypertension. Eur Heart J Cardiovasc Imaging. 2019;20(2):209-17.

13. Ley S, Mereles D, Puderbach M, Gruenig E, Schock H, Eichinger M, et al. Value of MR phase-contrast flow measurements for functional assessment of pulmonary arterial hypertension. Eur Radiol. 2007;17(7):1892-7.

14. Ley S, Mereles D, Risse F, Grunig E, Ley-Zaporozhan J, Tecer Z, et al. Quantitative 3D pulmonary MR-perfusion in patients with pulmonary arterial hypertension: correlation with invasive pressure measurements. Eur J Radiol. 2007;61(2):251-5.

15. Schafer M, Wilson N, Ivy DD, Ing R, Abman S, Browne LP, et al. Noninvasive wave intensity analysis predicts functional worsening in children with pulmonary arterial hypertension. Am J Physiol Heart Circ Physiol. 2018; 315(4):H968-H77.

16. Skrok J, Shehata ML, Mathai S, Girgis RE, Zaiman A, Mudd JO, et al. Pulmonary arterial hypertension: MR imaging-derived first-pass bolus kinetic parameters are biomarkers for pulmonary hemodynamics, cardiac function, and ventricular remodeling. Radiology. 2012;263(3):678-87.

17. Pandya B, Quail MA, Steeden JA, McKee A, Odille F, Taylor AM, et al. Realtime magnetic resonance assessment of septal curvature accurately tracks acute hemodynamic changes in pediatric pulmonary hypertension. Circ Cardiovasc Imaging. 2014;7(4):706-13.

18. Walkup LL, Tkach JA, Higano NS, Thomen RP, Fain SB, Merhar SL, et al. Quantitative magnetic resonance imaging of bronchopulmonary dysplasia in the neonatal intensive care unit environment. Am J Respir Crit Care Med. 2015;192(10):1215-22.

19. Higano NS, Spielberg DR, Fleck RJ, Schapiro AH, Walkup LL, Hahn AD, et al. Neonatal pulmonary magnetic resonance imaging of bronchopulmonary dysplasia predicts short-term clinical outcomes. Am J Respir Crit Care Med. 2018;198(10):1302-11.

20. Critser PJ, Higano NS, Tkach JA, Olson ES, Spielberg DR, Kingma PS, et al. Cardiac MRI evaluation of neonatal bronchopulmonary dysplasia associated pulmonary hypertension. Am J Respir Crit Care Med. 2019;201:73-82.

21. Bouchard A, Higgins CB, Byrd BF 3rd, Amparo EG, Osaki L, Axelrod R. Magnetic resonance imaging in pulmonary arterial hypertension. Am J Cardiol. 1985;56(15):938-42.

22. Dellegrottaglie S, Sanz J, Poon M, Viles-Gonzalez JF, Sulica R, Goyenechea M, et al. Pulmonary hypertension: accuracy of detection with left ventricular septal-to-free wall curvature ratio measured at cardiac MR. Radiology. 2007; 243(1):63-9.

23. Roeleveld RJ, Marcus JT, Faes TJ, Gan TJ, Boonstra A, Postmus PE, et al. Interventricular septal configuration at mr imaging and pulmonary arterial pressure in pulmonary hypertension. Radiology. 2005;234(3):710-7.

24. Sciancalepore MA, Maffessanti F, Patel AR, Gomberg-Maitland M, Chandra S, Freed $\mathrm{BH}$, et al. Three-dimensional analysis of interventricular septal curvature from cardiac magnetic resonance images for the evaluation of patients with pulmonary hypertension. Int J Card Imaging. 2012;28(5):1073-85.
25. Jobe AH, Bancalari E. Bronchopulmonary dysplasia. Am J Respir Crit Care Med. 2001;163(7):1723-9.

26. Tkach JA, Merhar SL, Kline-Fath BM, Pratt RG, Loew WM, Daniels BR, et al. $\mathrm{MRI}$ in the neonatal ICU: initial experience using a small-footprint 1.5-T system. AJR Am J Roentgenol. 2014;202(1):W95-W105.

27. Nagiub M, Kanaan U, Simon D, Guglani L. Risk factors for development of pulmonary hypertension in infants with bronchopulmonary dysplasia: systematic review and meta-analysis. Paediatr Respir Rev. 2017;23:27-32.

28. King ME, Braun H, Goldblatt A, Liberthson R, Weyman AE. Interventricular septal configuration as a predictor of right ventricular systolic hypertension in children: a cross-sectional echocardiographic study. Circulation. 1983; 68(1):68-75

29. Reisner SA, Azzam Z, Halmann M, Rinkevich D, Sideman S, Markiewicz W, et al. Septal/free wall curvature ratio: a noninvasive index of pulmonary arterial pressure. J Am Soc Echocardiogr. 1994;7(1):27-35.

30. Abraham S, Weismann CG. Left ventricular end-systolic eccentricity index for assessment of pulmonary hypertension in infants. Echocardiography. 2016; 33(6):910-5.

31. McCrary AW, Malowitz JR, Hornick CP, Hill KD, Cotten CM, Tatum GH, et al. Differences in eccentricity index and systolic-diastolic ratio in extremely lowbirth-weight infants with bronchopulmonary dysplasia at risk of pulmonary hypertension. Am J Perinatol. 2016;33(1):57-62.

32. Marcus JT, Gan CT, Zwanenburg JJ, Boonstra A, Allaart CP, Gotte MJ, et al. Interventricular mechanical asynchrony in pulmonary arterial hypertension: left-to-right delay in peak shortening is related to right ventricular overload and left ventricular underfilling. J Am Coll Cardiol. 2008;51(7):750-7.

33. Johns CS, Kiely DG, Rajaram S, Hill C, Thomas S, Karunasaagarar K, et al. Diagnosis of pulmonary hypertension with cardiac MRI: derivation and validation of regression models. Radiology. 2019;290(1):61-8.

\section{Publisher's Note}

Springer Nature remains neutral with regard to jurisdictional claims in published maps and institutional affiliations.
Ready to submit your research? Choose BMC and benefit from:

- fast, convenient online submission

- thorough peer review by experienced researchers in your field

- rapid publication on acceptance

- support for research data, including large and complex data types

- gold Open Access which fosters wider collaboration and increased citations

- maximum visibility for your research: over $100 \mathrm{M}$ website views per year

At BMC, research is always in progress.

Learn more biomedcentral.com/submissions 